\title{
Sentidos del intervalo: el giro digital en la semiótica de las
} culturas / Senses of the interval: the digital turn in the semiotics of cultures

\author{
Massimo Leone \\ (pág 91 - pág 103)
}

Las culturas cambian a medida que nuevos instrumentos de significación y comunicación surgen y se desarrollan en su interior, dando lugar a formas novedosas de inscripción y circulación del sentido. Nuevas tecnologías de la comunicación se implementan para satisfacer exigencias específicas de interacción humana, pero a menudo producen efectos socioculturales imprevistos. Las culturas contemporáneas siguen siendo, en gran medida, no digitales; por ejemplo, los individuos siguen viviendo en medioambientes urbanos materiales; sin embargo, las ciudades y, más en general, toda la herencia de las civilizaciones antiguas se está transformado bajo el influjo de las nuevas modalidades de comunicación digital. El ensayo se enfoca en dos cuestiones: ¿qué puede hacer la semiótica para el conocimiento de las culturas digitales? ¿Qué pueden hacer las culturas digitales para el mejoramiento de la semiótica?

Palabras clave: semiótica de la cultura, culturas digitales, intervalo, simulacros, alienación

Cultures change as new instruments of meaning and communication emerge and develop within them, giving rise to novel forms of inscription and circulation of meaning. New communication technologies are implemented to meet specific demands of human interaction, but often produce unforeseen socio-cultural effects. Contemporary cultures are still largely non-digital, for example individuals continue to live in material urban environments; nevertheless, cities and, more generally, all the inheritance of the ancient civilizations are being transformed under the influence of the new modalities of digital communication. The essay focuses on two questions: what can semiotics do for the knowledge of digital cultures? What can digital cultures do for the improvement of semiotics?

Keywords: cultural semiotics, digital cultures, interval, simulacra, alienation

Massimo Leone es catedrático de las Universidades de Turín y Shanghái. Email: massimo.leone@unito.it

Fecha de presentación: octubre de 2018. Fecha de aceptación: junio de 2019. Fecha de publicación: diciembre de 2019 
"I'm so scared of dying without ever being really seen. Can you understand?"

David Foster Wallace, Infinite Jest, 1996

\section{MECÁNICAS DIGITALES DEL CAMBIO CULTURAL}

Una pregunta fundamental en el estudio de las culturas concierne a la cuestión de si el cambio de tecnología comunicativa en una sociedad juega un papel central en la alteración de las culturas mismas. Por un lado, algunos investigadores contestan con una posición radical y señalan que, al mudar de tecnología de la comunicación, cambia de manera fundamental la manera en la que los individuos y los grupos humanos producen y comparten sentido (Flichy 2003). Por otro lado, otros estudiosos consideran que los instrumentos mismos de la tecnología de la comunicación son el producto de un cambio preexistente en las ideologías lingüísticas y semióticas que caracterizan un entorno cultural (Latour y Woolgar 1986).

Por ejemplo, se puede formular la hipótesis de que la introducción de la geolocalización, incluso a través de aplicaciones populares como Google Maps, ha cambiado y sigue cambiando el sentido humano del espacio en las comunidades que se sirven masivamente de estos dispositivos (Soro 2014), tal y como ocurre en la experiencia de turistas y viajeros, en particular, donde su utilización muda la configuración del lenguaje y de la interacción simbólica verbal. Una función lingüística esencial para el viajero predigital era la que Roman Jakobson definió como “conativa”: el viajero, por definición, se encontraba en un territorio, en una sociedad y en una cultura de los que no conocía nada, o conocía muy poco, o por lo menos conocía menos que los nativos, y entonces, por razones de curiosidad o simplemente para sobrevivir, se hallaba a menudo en la situación de tener que pedir y preguntar. El viajero predigital era alguien que tenía que preguntar continuamente, por ejemplo, la ubicación de un monumento, la dirección para llegar a un hotel, el precio de un objeto; además, el viajero predigital era también alguien que tenía que pedir favores incesantemente. Si viajaba solo, pedía frecuentemente a desconocidos que utilizaran su cámara para sacarle una foto.

El turista digital, al revés, puede explorar muchos territorios del planeta, o-por lo menos los que estén enlazados con la red digital global y sus servicios, sin pedir y sin preguntar. La geolocalización digital le permite hoy al viajero encontrar la mayoría o la totalidad de sus destinos sin preguntar nada a nadie. El dispositivo de la selfi o el accesorio del trípode con auto disparador dispensa de pedir a los demás que se conviertan en nuestros fotógrafos temporeros; hay, incluso, toda una serie de aplicaciones que no solo informan al viajero, sino le recomiendan dónde comer, dónde dormir, dónde escuchar música e incluso, dónde tener sexo o comprar substancias ilegales. En algunos países donde la digitalización de bienes y servicios es aún más desarrollada, como en China, por ejemplo, incluso se puede ir de compras en un mercadito callejero sin tener que hablar de precios con los vendedores, ya que el móvil contiene aplicaciones que pueden saber todo de los productos a través la lectura de sus códigos de barras. Hoy se puede viajar por un 
país digitalizado casi sin tener que utilizar el lenguaje verbal en su forma oral. Si antes un poco de conocimiento de la lengua local era necesario por lo menos para hablar con los choferes de taxi, ahora la geolocalización y aplicaciones como Uber y Didi han eliminado, incluso, esta necesidad.

El ejemplo del turista digital muestra que cuando en una "semiosfera" cambian las condiciones tecnológicas de la circulación del sentido, los efectos nunca son solamente locales, sino que abarcan toda una rama de conexiones que se desprenden a partir de un cambio particular. La digitalización del espacio urbano y de la navegación a su interior altera profundamente la calidad de la interacción lingüística entre nativos y viajeros, incluso la de nativos y migrantes. Los móviles son los instrumentos más eficaces que los migrantes poseen para reconstruir un entorno confortable en el territorio de llegada. Al mismo tiempo, los móviles incluso pueden volverse dispositivos de auto-segregación, ya que su aparente eficacia técnica no empuja a los viajeros a desarrollar una interacción verbal con los locales.

Con referencia al famoso cuadrado semiótico de las valorizaciones de Greimas y Floch, incluso se podría añadir que la eliminación de la interacción simbólica verbal oral produce resultados excelentes en las prácticas que estriben en una valorización esencialmente crítica, mientras que los resultados en el ámbito de la valorización estética son mucho más problemáticos. Por ejemplo, no es difícil imaginar un futuro en el que un chofer de taxi sea sustituido por un robot, o por un auto sin conductor. Los sistemas de geo-localización son tan sofisticados o, desde otra perspectiva, las habilidades cognitivas necesarias para conducir un taxi son tan poco sofisticadas, que no es absurdo prever una sustitución de esta figura profesional por una máquina, ya que, en efecto, muchos de los choferes de taxi contemporáneos, sobre todo en enormes metrópolis, son incapaces de hacer su trabajo sin la asistencia de un programa geo localizador que les indique el camino e incluso les sugiera cómo huir del tráfico.

En el ámbito de la valorización utópica, estética o lúdica, sin embargo, la inteligencia artificial de los algoritmos e incluso la inteligencia natural distribuida de los sistemas de reputación online no siempre es suficientemente aguda para captar y satisfacer los deseos del viajero. Uno consulta la lista de los mejores restaurantes de una ciudad según la clasificación de un sistema de rating como Tripadvisor y, con el paso del tiempo, cuanto más conocemos las ciudad, más la lista nos parecerá inadecuada. Muchos de los sistemas de rating tienden al populismo digital, en el sentido que restaurantes y hoteles que ya tienen una buena reputación siguen atrayendo muchos clientes y obteniendo muchas recensiones; mientras que pasar de la posición de outsider del rating a la de insider sigue siendo complicada (Leone 2017). Tener un amigo en una ciudad desconocida el cual, conociendo nuestros gustos, nos aconseje un restaurante, todavía es una práctica incomparablemente superior a la de confiar en un algoritmo que, basándose en las opiniones de viajeros precedentes, nos sugiera donde ir.

La sugerencia en el ámbito utópico-estético conlleva una dimensión humanística en la que los seres humanos todavía prevalesen. Lo mismo vale para las aplicaciones, cada vez más y más numerosas, que evalúan a los profesores. Un estudiante que elija sus cursos 
estribándose en estas estadísticas conseguiría seguir los profesores más populares y no necesariamente los más adecuados para su formación.

Este ejemplo indica que el impacto del cambio del marco tecnológico sobre la semiosfera no puede ser descrito por un metadiscurso general, sino por un metalenguaje que tenga en cuenta la diferencia de géneros discursivos que caracteriza a la semiosfera. La geolocalización digital, en nuestro ejemplo, le permite a un sujeto navegar en un territorio sin ser vinculado, a través de la lengua local, con el entorno social en el que está penetrando. El turista puede acumular experiencia de un territorio ajeno, de su sociedad y cultura - alimentando así el mercado que vende este producto existencial que es el geolocalizador - sin verdaderamente salir de la envoltura digital del espacio ajeno, la cual, en realidad, se convierte en su simulacro. Lo que introduce de manera impactante el principio de la alteridad en la experiencia del viajero o del turista resulta ser más y más el accidente: masas de viajeros bloqueadas en los aeropuertos de Londres por la erupción del volcán islandés sin acceso a informaciones útiles; muchedumbres de turistas paralizados en Indonesia por el terremoto, sin saber cuál será su destino, etc.

Recapitulando: el cambio de la tecnología de la comunicación seguramente afecta la formación del sentido. Según algunas teorías, la influencia sería radical, según otras, ya estaría preparada por el mismo cambio de ideología semiótica. Es probable que la medida del impacto mude según el género y, sobre todo, según la modalidad discursiva. La introducción de la geolocalización, por ejemplo, impermeabiliza el sentido del espacio en la esfera individual, incluso con relación a las experiencias, como el turismo, que se venden y se compran justamente como ocasiones para exponerse de manera más o menos aventurada a la alteridad. En este caso, sin embargo, el sentido del espacio se individualiza sobre todo en el marco de una práctica crítica de consumo del territorio y de su potencial para dar a conocer la otredad, mientras que en otros marcos más cualitativos el contacto con el otro ser humano, su lengua y su saber son fundamentales.

\section{UNA LECTURA ALTERNATIVA DEL CAMBIO CULTURAL}

Una lectura alternativa de esta influencia de la tecnología sobre el sentido y su comunicación podría ser la siguiente: no es la disponibilidad de algoritmos de geolocalización la que produce una fruición individualizada e incluso individualista del territorio, sino al revés, es el desarrollo hegemónico de una ideología semiótica individualista la que conduce a éxitos tecnológicos que traducen en la nueva materialidad digital lo que es ya una tendencia colectiva. Desde este punto de vista, el hecho que se pueda hoy visitar perfectamente una ciudad extranjera sin hablar con ninguno de los nativos para preguntarle o pedirle algo sólo es la última etapa de un largo proceso en el que la dimensión del sentido se ha ido paulatinamente autonomizando, confinándose en esferas discursivas siempre más ajustadas a lo que se percibe como el centro del yo.

La tecnología de la comunicación seguramente contribuye a cambiar las relaciones sociales y culturales, pero ella misma cambia en función de una dinámica más abstracta y 
profunda, la cual esencialmente coincide con una ideología semiótica, o sea con una cierta manera de entender el sentido, y la cual se articula en lo que Lotman hubiera llamado un "texto de la cultura", o sea una fórmula que abastece el núcleo fundamental de los textos que circulan en la semiosfera (Lotman 1996-2000 y 2018). Para identificar esta fórmula, y aún más a profundidad, para describir la ideología semiótica subyacente, es necesario, desde el punto de vista de una semiótica de la cultura, construir series que contengan textos distintos, en una extracción de muestras cuya metodología es muy compleja ya que se trata de una operación esencialmente cualitativa, no estadística, muy arriesgada, abductiva, y fundamentalmente guiada por el instinto del investigador.

Sin embargo, esta perspectiva le permitiría a uno no interpretar el impacto de la tecnología de la comunicación digital de manera determinista. Por ejemplo, es evidente que la presencia se vuelve más y más rarefacta en la comunicación entre individuos, incluso en las ocasiones donde tradicionalmente la presencia física del otro sería central. A muchos millenials de hoy les resultaría insufrible recibir una llamada telefónica de una potencial o hasta de una actual pareja sentimental. Llamar a un amante es algo que no se hace más. No sería "cool"; incluso sería una falta de respeto; una invasión en la privacidad del otro; en su burbuja personal. El nivel máximo de la intimidad hoy es representado por un mensaje vocal en WhatsApp, o sea por una huella de la voz y, por lo tanto, del cuerpo del amante que se pueda guardar, no escuchado, hasta cuando no se decida que el flujo cuotidiano de pensamientos, emociones y acciones del yo no esté listo para acoger al otro, exactamente en el momento en el que se permita una abertura de la burbuja personal hacia el exterior.

Sin embargo, estos mensajes grabados incluso resultan intolerables si la relación entre dos personas no es bastante íntima: escuchar la voz física del otro, y sobre todo sufrir todas las imperfecciones y los retrasos de la comunicación oral resulta intolerable, una especie de invasión en el tiempo propio del yo, guardado y defendido con todo el celo posible. Mucho mejor es, entonces, recibir unos mensajes escritos, cuidosamente redactados, corregidos y editados antes del envío, con su equipo de emoticones que matizan todo lo matizable, ironizan todo lo ironizable, desactivan toda posible amenaza de invasión en la esfera del otro.

La fórmula semiótica que produce estos comportamientos se hace macroscópica y hasta cómica en las situaciones de "citas digitales", en plataformas de mensajería como Tinder y Tam Tam, por ejemplo, en las que a menudo la relaciones consisten en un interminable intercambio aséptico de mensajes perfectamente estudiados los cuales nunca dan lugar a una ocasión de encuentro más arriesgado con el otro.

Sin embargo, como se ha subrayado varias veces, sería ingenuo pensar que las nuevas tecnologías de la comunicación digital nos hayan empujado hacia este tipo de relaciones. Al revés, es una cierta ideología semiótica de la relación entre personas que ha generado no tanto el deseo cuanto el espacio existencial para esta tecnología, la cual, como toda tecnología, no ha hecho otra cosa que potenciar una tendencia social que ya existía y para la cual ya existía un mercado. 


\section{HACIA UNA SEMIÓTICA DEL INTERVALO}

Describir los rasgos fundamentales de esta ideología semiótica no es fácil, pero se puede, por lo menos en parte, lograr abstrayendo los valores fundamentales que están debajo de sus varias manifestaciones. Pensadores como Sloterdijk y, desde otra perspectiva, Roberto Esposito (2009), han atribuido mucha importancia a una ideología de la separación, a una tendencia social generalizada de creación de fronteras inmunitarias alrededor del yo. Según Sloterdijk, la historia cultural contemporánea del mundo occidental estaría caracterizada por la creación de esferas particulares y a menudo monádicas, las cuales en la comunicación digital se configurarían como burbujas aislantes. Según Esposito, estas burbujas expresarían una ideología de la inmunidad en la que los individuos serían ahora incapaces de compartir su yo en un ámbito comunitario.

Estas interpretaciones son interesantes, pero sin embargo parecen algo inadecuadas con relación a un elemento de las sociedades actuales que, al revés, es macroscópico y omnipresente: los individuos, y sobre todo las nuevas generaciones, están obsesionados por el deseo de conectarse. Estar desconectado es lo peor que pueda pasar desde el punto de vista físico, tecnológico y existencial. En países que limitan de manera discrecional la posibilidad de viajar al extranjero como Irán o Cuba, por ejemplo, muchos jóvenes emigran hacia condiciones económicas, de hecho, peores de las que caracterizan su propio país, porque no pueden tolerar el límite existencial de no poder viajar. Viajar cuando y a donde uno lo desee se ha vuelto un elemento imprescindible de la calidad de la vida del joven contemporáneo. De manera análoga, en los sitios que alquilan apartamentos o habitaciones a viajeros y turistas como Airbnb, por ejemplo, los pisos sin conexión a Internet son mucho más baratos, exactamente porque la posibilidad de conectarse — incluso durante el viaje - es hoy un valor fundamental. En fin, no hay manifestación más evidente de esta obsesión conectiva que la cantidad de tiempo y energías cognitivas que los individuos contemporáneos gastan en las redes sociales digitales.

Por un lado, entonces, los individuos gozan de la separación que los nuevos medios de comunicación física y cognitiva les permiten lograr; por otro lado, estar separados de los demás es una condición intolerable para el sujeto contemporáneo, a menos que él mismo no lo persiga, justamente como pausa o paréntesis lujosamente snob en relación con la rutina. Hay individuos que pagan para retirarse a lugares donde Internet no llega, pero estos mismos individuos pagarían mil veces más para irse de estos lugares cuando lo quisieran. Estas observaciones, entonces, nos empujan hacia la dirección de pensar que el elemento fundamental de la ideología semiótica que esta debajo de las formas virales de la comunicación digital contemporánea es, de hecho, otra. No es la separación en forma de esferas, burbujas u otras topologías de aislamiento. Ella reside, al revés, en lo que, abstractamente, se podría definir como una especie de idealismo estético.

Pensadores como Sloterdijk y Esposito, esencialmente, subrayan la importancia del espacio y de la topología en la interpretación de la ideología contemporánea del sentido. Los individuos crean nuevas esferas en formas de burbujas digitales porque quieren separar su identidad de los entornos sociales. En este sentido, el rasgo fundamental de la ideología 
semiótica debajo de la comunicación digital contemporánea sería una especie de miedo a la alteridad, percibida como amenazadora de la integridad del yo. Las fronteras digitales con las que los individuos se rodean y se protegen en la vida cotidiana serian, entonces, una versión micro de las fronteras dentro de las que las sociedades se encierran a nivel macro.

Estas interpretaciones revelan características importantes de las sociedades contemporáneas y de sus comunicaciones digitales, pero habría que complementarlas con otras interpretaciones que subrayen más el valor y el sentido del tiempo a lado del sentido del espacio. Si la ideología semiótica fundamental de la semiosfera contemporánea contiene un elemento que las tecnologías de la comunicación digital contribuyen a enfatizar, este elemento no es solamente un deseo de aislamiento, o sea de separación en el espacio, sino un deseo de mediación, o sea de separación en el tiempo. Según esta interpretación, no es completamente correcto afirmar que los individuos quieran aislarse los unos de los otros por razón de un miedo generalizado a la alteridad; esto no explicaría, por ejemplo, el deseo de conexión que acabamos de mencionar. Al revés, los individuos contemporáneos quieren encontrar a los demás, quieren salir de su aislamiento, y de hecho temen la soledad aún más que las generaciones precedentes, pero no quieren que el contacto con los otros sea inmediato, o sea que tenga lugar sin el interfaz de algo que interponga, no una separación espacial de defensa, sino un intervalo temporal de preparación.

El intervalo, en la ideología semiótica contemporánea, parece mucho más central que la frontera. Si la comunicación es esencialmente un pasaje de contenido semántico de A hacia $B$, subsiste un deseo creciente que este pasaje no tenga lugar de manera simultánea, sino de tal forma que A pueda controlar este contenido de manera eficaz y, posiblemente, exhaustivo. Este deseo conlleva un corolario de dimensiones macroscópicas: no hay nada más molesto, en la semiosfera contemporánea, que la comunicación cara a cara, ya que ésta constitutivamente requiere una eliminación radical del intervalo en el pasaje de sentido de un ser humano al otro.

Muchos analistas de la comunicación contemporánea han criticado sus formas digitales, por ejemplo, los emojis, porque no tienen la capacidad de traducir de manera adecuada los matices de la emotividad humana. Esto es cierto, pero probablemente no es el asunto principal. Lo inquietante de la comunicación digital contemporánea no es que sea imperfecta en su capacidad de vehicular el sentido, sino que sea siempre diferida. El emoji no tendría que preocupar tanto porque no traduce todos los matices de la emoción humana, incluso porque un número creciente de emojis, gifs, stickers y otras imágenes digitales ayudan al individuo que quiere expresar emociones matizadas en las redes sociales digitales (Danesi 2016). Al revés, estas formas preocupan porque siempre encarnan la expresión de una emoción diferida, controlada, formateada, editada en su versión digital antes de ser manifestada al otro.

En otras palabras, la obsesión contemporánea por el intervalo es una manifestación de la exigencia ansiosa de controlar, en la comunicación, todo lo que es incontrolable, y principalmente el cuerpo. Sin embargo, en este contexto también es preciso subrayar que no es la disponibilidad de la comunicación digital lo que conlleva a una desaparición del cuerpo; al revés, esta disponibilidad es un efecto de la ideología semiótica que les sugiere 
a los individuos no estar en el mundo directamente, con su propio cuerpo, sino a través de su simulacro temporalmente diferido, un simulacro gracias al cual el cuerpo pueda ser controlado, programado, purgado de sus rasgos antes de manifestarse.

En el marco de esta hipótesis, resulta fundamental, entonces, enfocarse en algunos asuntos que conciernen una semiótica del intervalo. Primero, ¿cómo es posible que el intervalo, o sea la posibilidad de diferir la comunicación del cuerpo para controlar sus efectos comunicativos, sea tan central en una semiosfera en la que, al revés, la inmediatez es a menudo propuesta, vendida y comprada como valor? Segundo, si el intervalo es, efectivamente, un rasgo esencial de la ideología semiótica contemporánea, ¿cuáles son sus motivaciones o sea, por qué razones se producen a la vez el miedo de manifestar el cuerpo, directa e inmediatamente, y el deseo de servirse de simulacros que permitan un control previo del sentido que desde el cuerpo se desprende? Tercero, ¿cuáles son las raíces históricas, a largo plazo, de esta huida de la comunicación cara a cara? Cuarto, último y fundamental punto, ¿cuál es el efecto antropológico profundo de esta marginalización progresiva del encuentro directo con la cara y el cuerpo del otro?

La primera pregunta, sobre la relación entre intervalo e inmediatez, se puede contestar con un ejemplo concerniente al pasaje de la fotografía analógica a la fotografía digital. Por un lado, esta transición parece coincidir con una subida del nivel de espontaneidad en la producción, circulación y recepción de las fotos. La digitalización de la fotografía, la miniaturización de las cámaras de foto y, sobre todo, su incorporación en los teléfonos móviles con la posibilidad de conectar de inmediato las fotos con las redes sociales digitales, han conllevado a una progresiva difusión de prácticas fotográficas digitales, con la oportunidad, para cualquiera, de contribuir en todo momento a estos nuevos circuitos de la comunicación. La fotografía analógica necesitaba de una preparación y, sobre todo, de un desarrollo que no solamente requería un aporte profesional, sino que implicaba un intervalo entre el tiempo de producción de la foto y el tiempo de su recepción. Ahora este intervalo con la fotografía digital se ha reducido hasta anularse, pero otros tipos de intervalo intervienen para alejar la representación fotográfica del cuerpo.

Uno de estos tipos es fundamental en la comunicación visual contemporánea: el filtro. Todo smartphone tiene en su dotación originaria la capacidad de transformar una foto digital antes de ser puesta en circulación en las redes sociales. Por consiguiente, los aparatos fotográficos digitales podrían ser una ocasión de inmediatez neorrealista, pero, de hecho, se vuelven dispositivos de preparación minuciosa de simulacros. Casi nadie dispara en las redes sociales fotografías sacadas con un móvil sin editarlas cuidadosamente. Esto se puede comprobar fácilmente observando cómo las fotografías que cotidianamente se acumulan en redes sociales digitales como Facebook o Instagram se conforman mucho más que sus antecedentes analógicos a patrones discursivos bastante estandarizados por tendencias y modas de la representación.

El fenómeno es macroscópico en las aplicaciones digitales de "emparejamiento" ("dating"), donde nadie se puede permitir encontrar una imagen sin filtros del cuerpo de los otros, ni exhibir su propia imagen sin haberla -atentamente- conformado a un modelo 
hegemónico de deseabilidad. Incluso las fotos digitales que deberían transmitir un sentido de espontaneidad encarnan un modelo algo populista de inmediatez, una mise en scène que finge no serlo, utilizando filtros y formatos cuyo efecto sería justamente el de transmitir la impresión de su ausencia. En el digital dating de países asiáticos como China o Japón, el deseo de transformar el cuerpo, y sobre todo el cuerpo femenino, gracias a un intervalo temporal entre la producción de la imagen y su circulación -intervalo en el que se hace posible una postproducción de los simulacros del yo - se configura según tendencias evidentemente neocoloniales, por ejemplo, con la superposición de grandes ojos digitales occidentales sobre el rostro de las mujeres que se ofrecen para el emparejamiento digital.

En lo que concierne la segunda pregunta, sobre las motivaciones que empujan la ideología semiótica contemporánea a estructurarse alrededor de la exigencia del intervalo, incluso produciendo tecnologías y dispositivos que favorecen esta tendencia cultural, la respuesta tiene que ser multiforme e hipotética. Como se ha subrayado antes, no parece totalmente satisfactoria la interpretación que le atribuye al miedo a los demás y, por lo tanto, a un deseo de burbujas inmunizantes a la huida del contacto directo e inmediato con el cuerpo del otro. Al revés, los individuos contemporáneos buscan un contacto con la alteridad, pero este contacto es detenidamente preparado para que tenga lugar en las mejores condiciones. Queremos un intervalo en el que podamos editar la imagen de nuestro yo, no porque nos de miedo encontrar al otro, sino porque estamos continuamente vendiendo la imagen de nosotros y, sobre todo, la de nuestros cuerpos.

¿Cuál es la razón, entonces, por la que nos preocupa tanto predisponer un simulacro digital de nuestra identidad que esté completamente desprovisto de imperfecciones, faltas, errores, descuidos, detalles sin control? ¿Qué nos empuja a formatear nuestro cuerpo como si fuera el texto de un correo electrónico, leído y releído varias veces antes de ser enviado? Una de las motivaciones quizás consista en el hecho de que el capitalismo avanzado nos obliga a proponer continuamente un micro-espectáculo de nosotros mismos, ofrecido para que los demás alaben y aprueben o, al revés, critiquen y rechacen. Un largo recorrido histórico y cultural ha constituido un modelo hegemónico de deseabilidad social, modelo que es macroscópicamente evidente en la presentación del cuerpo pero que subyace, también, a toda forma de significación destinada a la recepción ajena. Este modelo es el modelo de la continencia del yo, de la necesidad de moldear su manifestación de manera cuidadosa antes que encuentre la mirada o los sentidos de los demás.

Esta tendencia parecería totalmente contraria a las manifestaciones del populismo estético, por ejemplo, el que actualmente se desprende de la imagen de hombres políticos que, en Italia como en otros países, se presentan y se muestran a sus electores pasados, presentes y futuros sin ningún filtro, enseñando su cuerpo desnudo en playas o piscinas veraniegas. Estas imágenes se interpretan comúnmente como una prueba del nivel de mala educación general, como si la semiosfera fuera caracterizada por la evolución de una ideología semiótica que predica la espontaneidad hasta en la presentación del cuerpo e incluso en las situaciones tradicionalmente formales. Sin embargo, esta interpretación no es adecuada para entender el éxito mundial de la estética populista. La población se apasiona al cuerpo aparentemente espontáneo del líder justamente porque ve y admira en él 
la capacidad de rechazar las convenciones que, al revés, regulan la incesante evaluación a la que todo cuerpo "normal" está sometido. Si en el pasado la fascinación con el cuerpo del poderoso estaba relacionada con la capacidad del líder, de adecuarse más perfectamente que los otros, al canon estético vigente, hoy la fascinación con el cuerpo del líder populista es porque se admira su capacidad de rechazar lo que, para los comunes mortales, es una necesidad, o sea, aprovechar un intervalo para poder adecuar el cuerpo y la persona a lo que la sociedad les requiere.

La tercera pregunta, sobre las raíces históricas de la ideología semiótica que se expresa incluso en las nuevas tecnologías de comunicación digital, es muy compleja. Solamente se puede formular una hipótesis de respuesta que seleccione algunos elementos salientes de la historia de la comunicación en las semiosferas occidentales. Probablemente, una de las cesuras fundamentales en esta historia es constituida por el pasaje de una antropología de la comunidad a una del individuo, pasaje que coincidió con el inicio de lo que llamamos "la edad moderna”. En una antropología de la comunidad, el individuo no vive oprimido por la ansiedad de presentar una imagen de sí mismo que los otros miembros incesantemente juzguen y evalúen en el marco de tendencias estéticas continuamente fluctuantes. En esta antropología pre-moderna, al revés, cada individuo recibe un papel predeterminado, a menudo heredado como consecuencia del hecho de nacer en un entorno social o incluso en una familia, y la tarea por cumplir no es caracterizada por una exigencia de improvisación, sino por una de adecuación. Las clases burguesas incluso disponen de guías codificadas y hasta escritas para aprender cómo conformar todos sus comportamientos en el ámbito de la comunidad, por ejemplo, bajo la forma de los manuales de buenas maneras que han circulado en Europa, al menos desde el Renacimiento. Pero también las clases que no tienen acceso a esta formación codificada se apoyan en un sentido común el cual no abarca solamente nociones compartidas, sino también maneras de relacionarse con los demás.

El pasaje de esta antropología de la comunidad a una del individuo se comprueba perfectamente, en toda su radicalidad, estudiando lo que se podría definir "el lenguaje de la presentación". Como sugiere la perspectiva etnometodológica, en las comunidades complejas siempre surge la necesidad de codificar formas semióticas que permitan a una persona iniciar una relación social con un desconocido o con un grupo de desconocidos. Solamente en los grupos humanos tribales nunca se manifiesta la exigencia de empezar nuevas relaciones sociales, todos se conocen entre sí. Ocurre lo contrario en las comunidades más extensas, se codifican unas fórmulas de presentación las cuales persiguen el objetivo comunicativo de transformar a un perfecto desconocido en un conocido o por lo menos en un conocido potencial. Estas fórmulas varían a la vez sincrónica y diacrónicamente. Típicamente, ellas implican que, al presentarse a un desconocido, un individuo pronuncie algo en el discurso verbal, pero al mismo tiempo, en muchas culturas, que acompañe esta fórmula oral con otros elementos no verbales, como unos gestos, unas expresiones faciales, un movimiento del cuerpo y una modificación codificada de la relación proxémica con el cuerpo del desconocido.

El conjunto de estos signos verbales y no-verbales persigue el objetivo de marcar la distinción entre un encuentro con un desconocido que no dé lugar a una nueva relación 
social y un encuentro que, al revés, se entienda, pueda redefinir una geometría de relaciones al interior de la comunidad. Todas las culturas prevén, además de estos códigos de presentación, también unos códigos de introducción, los cuales deben ser adoptados por un individuo en el momento de establecer, o por lo menos en la tentativa de establecer, una nueva relación entre individuos o grupos que no se conozcan.

Los códigos de presentación y de introducción normalmente son muy antiguos, en algunos casos reciben una codificación incluso escrita en manuales de correcto comportamiento - como el manual de buenas maneras de Giovanni della Casa, el Galateo, por ejemplo - y, como se ha indicado antes, mudan en el tiempo y en el espacio. Tradicionalmente forman parte del sentido común de un grupo humano, mientras que hay que aprenderlos cuando se desee presentarse o introducir personas en un contexto ajeno. En el aprendizaje de otra lengua, normalmente estos códigos se estudian. Quien aprenda francés en Italia, por ejemplo, usualmente aprende que los varones se presentan entre ellos como en Italia, diciendo su nombre y estrechándose mutuamente la mano derecha, con una ligera sonrisa en la cara, mientras que la presentación entre mujeres y entre hombre y mujer prevé una variante de género la cual incluye "la bise", o sea dos o tres besitos rápidos sobre ambas mejillas, empezando por la izquierda. Estos códigos mudan no solamente en el pasaje de una cultura a otra, sino también según los contextos sociales de presentación e introducción, con relación a variables como la edad, el género y el estatus social de los individuos que toman parte a esta "escena de presentación".

El extranjero es, típicamente, un individuo que no sabe cómo presentarse o introducir otras personas en una comunidad. La gente comprenderá su intento, pero sus palabras y sus gestos serán inadecuados, incluso algo inapropiados y ridículos de acuerdo con los códigos vigentes. Un francés que intente hacer "la bise" introduciéndose a una joven mujer en Italia, por ejemplo, resultaría, por lo menos, exótico.

De manera análoga, el individuo con pocos "social skills" será incapaz de modular las fórmulas de introducción y presentación en su propio entorno social; por ejemplo, olvidando respetar las reglas codificadas y hasta escritas que prescriben quién tiene que presentarse primero a quién y con qué fórmulas según el género, el estatus y la edad de los individuos presentes. Por ejemplo, un individuo italiano joven que presente primero una mujer a un hombre en vez de presentar primero el hombre a la mujer daría la impresión de no haber absorbido perfectamente los códigos de presentación e introducción vigentes en su contexto social.

Todas estas fórmulas, con sus variedades diacrónicas y sincrónicas y sus matices de distinción social, son una herencia de la época premoderna, o sea de una etapa en la evolución de la semiosfera en la que incluso el establecimiento de nuevas relaciones sociales no ocurría en el marco de la improvisación individual, sino según patrones que la comunidad codificaba y hasta traducía en textos y manuales. ¿Pero cómo tiene lugar, al revés, la presentación entre desconocidos en las redes sociales digitales?

En muchos casos, ni siquiera tiene lugar. "Pedir la amistad" en Facebook o en otra red social análoga tiene muy poco que ver con la situación de presentarse a alguien en la 
vida off-line y hacérselo amigo. Facebook, por ejemplo, prevé la posibilidad de acompañar una petición de amistad con un pequeño texto de explicación, pero la verdad es que casi nadie la utiliza. Pedimos la amistad en Facebook no con un texto y aun menos con una fórmula codificada, sino a través de la presentación de nuestro perfil, donde la imagen que hemos elegido como la más representativa de nuestra personalidad juega un papel esencial.

En algunos casos, siempre más infrecuentes, la persona a la que pedimos la amistad nos ha encontrado, aunque sea muy brevemente, cara a cara en el mundo off line; de manera más y más común, sin embargo, se pide la amistad a desconocidos porque son "amigos de amigos" en Facebook, porque son conocidos por lo que hacen en la vida, pero la razón principal por la que se pide la amistad a alguien es que su perfil nos gusta, su imagen nos atrae, el conjunto de informaciones que se desprende de su página Facebook nos cautiva. De hecho, cuando damos y pedimos la amistad en Facebook esto tiene menos y menos que ver con lo que somos en la vida no digital; al revés, nos volvemos amigos no de personas, sino de simulacros de personas, de simulacros cuyos cuerpos físicos correspondientes ni siquiera nos apetece mucho encontrar en la realidad, o si los encontramos, la situación es a menudo embarazosa, exactamente porque lo que encontramos en la realidad siempre es algo decepcionante en relación a su preconfeccionada imagen digital, siempre excede la imagen utópica de un cuerpo que uno se hace estribándose en la retórica de su presentación digital.

\section{CONCLUSIONES: LA SEDUCCIÓN DIGITAL PERMANENTE}

Es normal en muchas culturas que, en el momento de la seducción, durante una primera cita, por ejemplo, una potencial pareja se presente el uno al otro mediante una imagen idílica de sí mismos, a la vez que reciben con benevolencia la imagen idílica que uno está produciendo durante la seducción. Los condicionamientos sociales de esta forma de entender el inicio de una relación de pareja son evidentes.

Pudiera haber un modelo alternativo, por ejemplo, una retórica de la captatio malevolentiae: durante la primera cita, uno muestra aquellos aspectos que está consciente son los más intolerables de su personalidad, dejando que la otra persona se enamore de sus defectos, o que, al menos, los considere como tolerables. El problema, sin embargo, no es el marketing vigente de la seducción interpersonal, sino que esta retórica se ha vuelto hegemónica hasta abarcar toda forma de interacción social. Hoy día vivimos como si estuviéramos siempre en una primera cita, sumergidos en una esfera de seducción recíproca donde el encuentro con el otro no está guiado más por las convenciones del sentido común, sino por la improvisación ansiosa, donde sabemos que la percepción fugaz de nuestro simulacro digital puede determinar el hecho de que seamos aceptados o rechazados y donde nosotros mismos establecimos relaciones sociales guiados por simulacros digitales efímeros.

Ya que ningún marco comunitario nos tranquiliza en nuestras relaciones sociales y ya que lo que acontece en la comunicación se torna el resultado exclusivo de nuestras decisiones estratégicas, presentarse a los demás sin reflexión previa y sin la posibilidad de construir, en el intervalo, un simulacro utópico de nosotros mismos se hace una práctica 
antisocial, una invasión de la sensibilidad digital de los demás. Manifestar al mundo la verdad de un cuerpo se ha vuelto un acto obsceno.

\section{REFERENCIAS BIBLIOGRÁFICAS}

DANESI, M. (2016) The Semiotics of Emojis: The Rise of Visual Language in the Age of the Internet. London y Nueva York, NY: Bloomsbury.

ESPOSITO, R. (2009) Comunidad, inmunidad y biopolítica, trad. del italiano de A. García Ruiz. Barcelona: Herder.

FLICHY, P. (2003) L'innovation technique: récents développements en sciences sociales, vers une nouvelle théorie de l'innovation. Paris: Éd. la Découverte.

LATOUR, B. y S. WOOLGAR (1986) Laboratory Life: The Construction of Scientific Facts. Princeton, NJ: Princeton University Press.

LEONE, M. (2017) "Semiótica de la reputación", Signa 26: 245-268.

LOTMAN, I.M. (1996-2000) La semiosfera, trad. del ruso de D. Navarro, Madrid, Cátedra.

- (2018) La semiosfera, trad. del ruso de D. Blanco, Lima: Universidad de Lima, Fondo editorial.

SLOTERDIJK, P. (1998-2004) Sphären, 3 vols, Frankfurt am Main: Suhrkamp Verlag; traducción del alemán de I. Reguera (2003-2006) Esferas, 3 vols, Madrid: Siruela.

SORO,E. (2014) "Las ciudades en la Web. Barcelona y Turín: el storytelling del turismo y del ocio". Tesis de doctorado, Universitat Autònoma de Barcelona, Departament de Periodisme i de Ciències de la Comunicació, dirs. M.R. Lacalle Zalduendo y M. Leone. Barcelona: Universitat Autònoma de Barcelona; disponible en el sitio web https://ddd.uab.cat/record/127122 
